\title{
Morphology of Dorsal Venous Arch of Hand: A Cadaveric Study
}

\author{
Nripendra Tiwari, ${ }^{1}$ Deepesh Budhathoki, ${ }^{1}$ Iju Shrestha, ${ }^{1}$ Ram Timsina, ${ }^{1}$ Santosh Kumar Shah, ${ }^{2}$ Banshi \\ Krishna Malla ${ }^{3}$ \\ ${ }^{1}$ Department of Anatomy, Kathmandu Medical College, Duwakot, Bhaktapur, ${ }^{2}$ Central Department of Statistics, \\ Tribhuvan University, Kirtipur, ${ }^{3}$ Department of Anatomy, Kathmandu Medical College, Duwakot, Bhaktapur, Nepal.
}

\begin{abstract}
Background: Venous network of hand is superficially placed and is easy to trace for clinical purposes. Cephalic vein on lateral aspect and basilic vein on medial aspect of the hand are clinically important for invasive and surgical procedures. Thus the study of cephalic and basilic veins at dorsal venous arch of hand was dissected to observe for length of dorsal venous arch and the diameter and thickness of cephalic and basilic veins. Methods: This is a cross-sectional observational study conducted in 50 hands of cadavers (36 hands of male cadavers, 14 hands of female cadavers) in Department of Anatomy, Kathmandu Medical College Teaching Hospital, Duwakot. Cadavers were performed to measure the length of dorsal venous arch, diameter and thickness of cephalic and basilic vein on dorsum of hands Results: The mean \pm s.d. length of dorsal venous arch in male cadaver $(19.03 \pm 2.84 \mathrm{~cm}$.) was significantly greater than in female $(16.51 \pm 1.36$ $\mathrm{cm}$.). There was no significant difference in length of dorsal venous arch on right $(18.22 \pm 2.47 \mathrm{~cm}$. $)$ and left side $(18.42 \pm 3.05 \mathrm{~cm}$.) in either sex. The mean \pm s.d thickness of basilic vein $(0.10 \pm 0.01 \mathrm{~mm})$ in either sex was significantly greater than that of cephalic vein $(0.09 \pm 0.01 \mathrm{~mm})$. Conclusions: The length of the dorsal venous arch in male cadavers was found significantly greater than in female cadavers. The diameters based on external and internal circumference of basilic veins was found to be more than diameter of cephalic veins in both male and female cadavers. The thickness of basilic vein was found to be more $(0.10 \pm 0.01 \mathrm{~mm})$ than that of cephalic vein $(0.09 \pm 0.01 \mathrm{~mm})$ in cadaver of both sexes.
\end{abstract}

Keywords: basilic vein; cephalic vein; venous network of hand.

\section{INTRODUCTION}

The methodology of examination of the morphology of the venous system is quite difficult task. Measurement taken in vivo might be erroneous because of subjective opinion of an investigator. The study on cadavers thus can deliver much reliable information. ${ }^{1}$ The cephalic and basilic veins differ considerably in localization, caliber and thickness. These veins are clinically important for venipuncture, blood donation, blood collection and intravenous transfusion in emergency treatment of hypovolumic shock. ${ }^{2}$ These veins also play role in plastic surgeries. ${ }^{3}$ Basilic vein is used for introducing cardiac catheter and is the best available conduit for arterio-venous fistula. ${ }^{4}$ However unintentional arterial puncture during cephalic vein cannulation cannot be avoided. ${ }^{5}$ The clinician must have the sound knowledge of the common sites at which these superficial veins like cephalic and basilic veins are found with its different variations in order to expose them. ${ }^{6}$ Thus the aim of the present study is to access the dorsal venous network of hand in cadavers.

\section{METHODS}

The study was conducted from April 2016 to October 2018 after fulfilling the steps necessary for conducting the research. A cross-sectional descriptive study was done. The venous system of hand showing dorsal venous arch with cephalic and basilic veins was fine dissected in 50 hands (36 hands of male cadavers, 14 hands of female cadavers) in Department of Anatomy at Kathmandu Medical College Teaching Hospital (KMCTH), Duwakot. Structured proforma was used to collect the data. Preparation of the cadavers were done for newly arrived body to the department by passing standard solution into femoral artery using chemicals like $40 \%$ formaldehyde, glycerine, carbolic acid, potassium carbonate, thymol, water etc. in standard appropriate proportion for embalmment. Open fine dissection of dorsum of hand was performed and the veins were painted blue after exposing and making it dry with the help of painting brush of sizes 1, 2, 3 and 4.The dissection instruments like Bard Parker handle and

Correspondence: Dr. Nripendra Tiwari, Department of Anatomy, Kathmandu Medical College, Duwakot, Bhaktapur, Nepal. Email: nriti2000@gmail.com. Phone: +977-9851130143. DOI: 10.3126/jcmsn.v15i2.23294. Article received: 2019-03-26. Article accepted: 2019-06-15. 
blade, toothed and fine forceps, sharp and blunt scissors, metallic hook, suture thread, cotton and gauge were used. Digital Slide Caliper, metallic and plastic scales were used for measurement of dimensions. All exposed structured were photographed in close and distant views by Digital Camera, 14.5 Mega Pixel, manufactured by Sony Company (Figure 4).

Green and blue clothes were used under the dissected structure to prevent anti light of camera. Length of the dorsal venous arch was measured
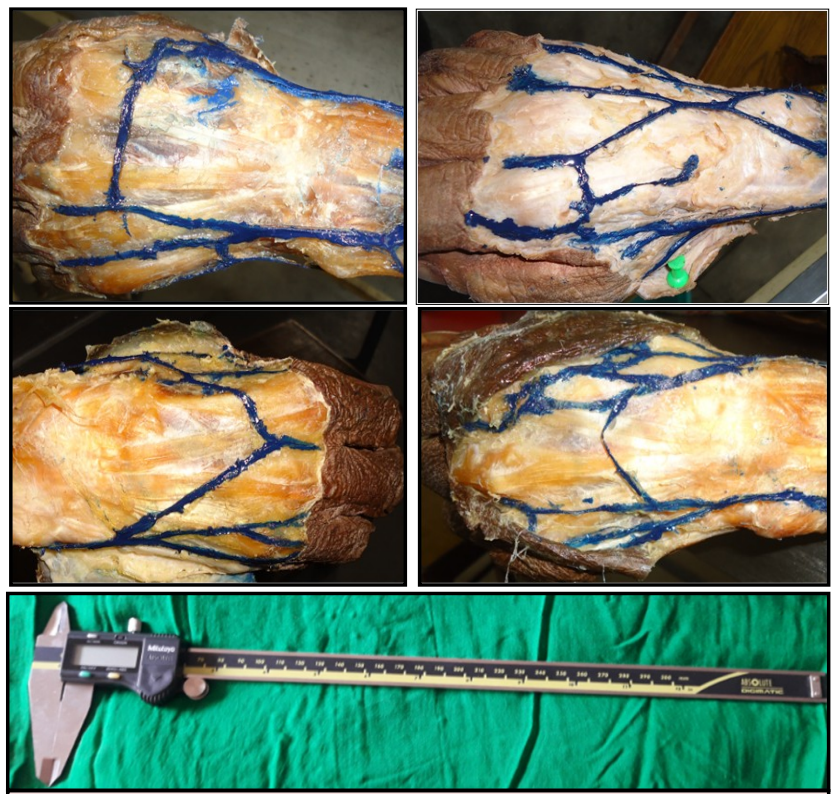

Figure 4. Dissection showing Dorsal Venous Arch with Digital Caliper used for the measurement of the veins.

using black suture thread spreading over dorsal venous arch from styloid process of radius to styloid process of ulna of the same hand of an individual. The total length of dorsal venous arch was calculated by adding length of fifth vein on medial aspect of hand, length of thumb vein on lateral aspect of hand and length of dorsal digital vein of middle three fingers. The measured length of thread on dorsal venous arch was then transferred into unit of centimeter in metallic scale recorded into structured proforma. The external circumference followed by internal circumference of the cephalic and basilic veins was measured using digital caliper by giving linear incision to the veins and gently stretching the wall of the veins flat near styloid process of radial and ulnar side of the hand after exposing the dorsal venous arch of the hand in cadavers. The external diameter of veins based on external circumference and internal diameter of veins based on internal circumference was calculated by dividing the circumference of the respective veins by pi $(=22 / 7)$ as universal formula for finding circumference is equal to product of pi and diameter. Then thickness of the veins was calculated by subtracting internal diameter of veins from external diameter of respective veins. Data collected was compiled in Microsoft Office Excel 2007 and further analyzed by SPSS version 20. Mean and standard deviation were calculated.The independent t-test was used to compare the significant difference between two means between the study variables. $p$ value $<0.05$ was considered as statistically significant.

\section{RESULTS}

The mean \pm s.d. length of dorsal venous arch in male cadavers was significantly greater $(19.03 \pm 2.84 \mathrm{~cm})$ than in female cadavers $(16.51 \pm 1.36 \mathrm{~cm})$ among dorsum of 50 hands of 25 cadavers available at

\begin{tabular}{|c|c|c|c|c|c|}
\hline Sex & $\mathbf{N}$ & Mean & SD & \multirow{3}{*}{$\begin{array}{l}\text { t-test } \\
4.22\end{array}$} & \multirow{3}{*}{$\begin{array}{c}\begin{array}{c}\text { p- } \\
\text { value }\end{array} \\
<0.001\end{array}$} \\
\hline $\begin{array}{l}\text { Male Cadavers in } \\
\text { both hands }\end{array}$ & 36 & 19.03 & 2.84 & & \\
\hline $\begin{array}{l}\text { Female Cadavers in } \\
\text { both hands }\end{array}$ & 14 & 16.51 & 1.36 & & \\
\hline \multicolumn{6}{|l|}{ Dorsum of Hands } \\
\hline $\begin{array}{l}\text { Right hand of male } \\
\text { and female cadavers }\end{array}$ & 25 & 18.22 & 2.47 & \multirow{2}{*}{0.27} & \multirow{2}{*}{0.792} \\
\hline $\begin{array}{l}\text { Left hand of male } \\
\text { and female cadavers }\end{array}$ & 25 & 18.42 & 3.05 & & \\
\hline
\end{tabular}

Department of Anatomy, Kathmandu Medical College Teaching Hospital (KMCTH) (Table1).

There was no significant difference in length of dorsal venous arch on right $(18.22 \pm 2.47 \mathrm{~cm})$ and

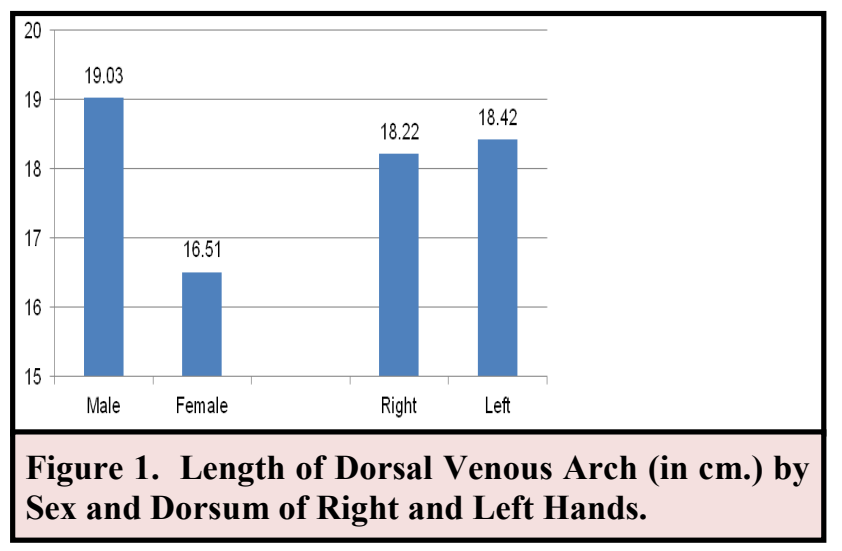

left side $(18.42 \pm 3.05 \mathrm{~cm})$ in either sex (Table1, Figure 1).

No significant difference was observed in diameter of cephalic vein based on its external circumference in male cadavers $(2.97 \pm 0.08 \mathrm{~mm})$ and female cadavers $(2.93 \pm 0.07 \mathrm{~mm})$. However the diameter of basilic vein based on its external and internal circumference respectively was significantly greater in male cadavers $(3.44 \pm 0.09 \mathrm{~mm}$ and 


\begin{tabular}{|c|c|c|c|c|c|c|c|c|}
\hline \multicolumn{9}{|c|}{$\begin{array}{l}\text { Table 2. Diameter and thickness (in } \mathrm{mm} \text { ) of Cephalic } \\
\text { and Basilic Veins. }\end{array}$} \\
\hline \multirow{2}{*}{ Veins } & \multicolumn{3}{|c|}{ Male Cadavers } & \multicolumn{3}{|c|}{ Female Cadavers } & \multirow{2}{*}{ t-test } & \multirow{2}{*}{ p-value } \\
\hline & $\mathbf{N}$ & Mean & SD & $\mathbf{N}$ & Mean & SD & & \\
\hline \multicolumn{9}{|c|}{ Based on External Circumference } \\
\hline Cephalic & 36 & 2.97 & 0.08 & 14 & 2.93 & 0.07 & 1.62 & 0.113 \\
\hline Basilic & 36 & 3.44 & 0.09 & 14 & 3.35 & 0.1 & 3.02 & 0.004 \\
\hline \multicolumn{9}{|c|}{ Based on Internal Circumference } \\
\hline Cephalic & 36 & 2.88 & 0.09 & 14 & 2.87 & 0.04 & 0.4 & 0.693 \\
\hline Basilic & 36 & 3.35 & 0.09 & 14 & 3.26 & 0.1 & 3.09 & 0.003 \\
\hline \multicolumn{9}{|c|}{ Thickness } \\
\hline Cephalic & 36 & 0.09 & 0.01 & 14 & 0.09 & 0.01 & 1.98 & 0.053 \\
\hline Basilic & 36 & 0.1 & 0.01 & 14 & 0.1 & 0.01 & -0.37 & 0.711 \\
\hline
\end{tabular}

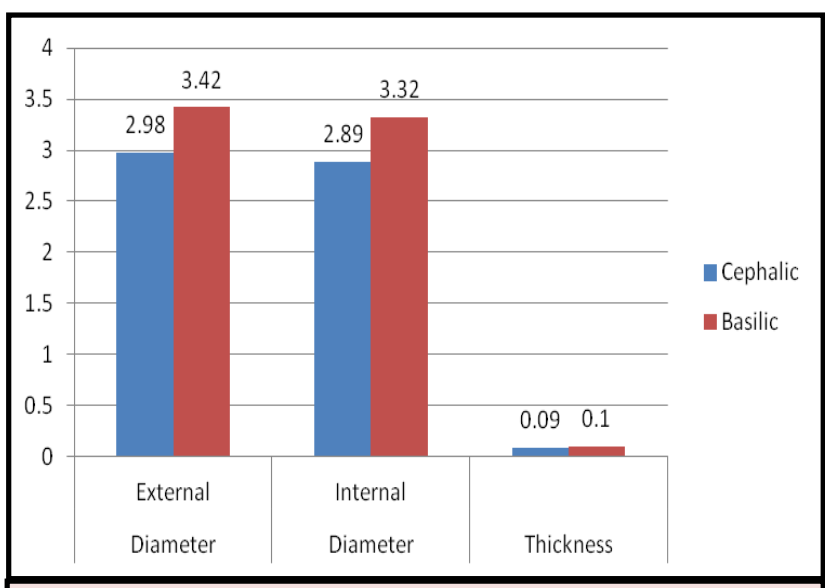

Figure 2. Diameter and thickness of cephalic and Basilic Veins.

$3.35 \pm 0.09 \mathrm{~mm})$ than in female cadavers $(3.35 \pm 0.10$ $\mathrm{mm}$ and $3.26 \pm 0.10 \mathrm{~mm}$ ) (p-value 0.003) (Table 2).

The mean diameter of basilic vein based on external and internal circumference respectively for dorsum of right hand was $3.42 \pm 0.11 \mathrm{~mm}$ and $3.32 \pm 0.10 \mathrm{~mm}$ and for left hand was $3.42 \pm 0.09 \mathrm{~mm}$ and $3.32 \pm 0.09 \mathrm{~mm}$. The mean diameter of cephalic vein based on external and internal circumference respectively for dorsum of right hand was $2.98 \pm 0.08 \mathrm{~mm}$ and $2.89 \pm 0.08 \mathrm{~mm}$ and for left hand was $2.93 \pm 0.08 \mathrm{~mm}$ and $2.86 \pm 0.07 \mathrm{~mm}$. These results showed that the mean diameters based on external and internal circumference of basilic veins was found to be more than diameter of cephalic veins in both male and female cadavers. The mean diameter of cephalic vein based on external and internal circumferences respectively on dorsum of right hand was more $(2.98 \pm 0.08 \mathrm{~mm}$ and $2.89 \pm 0.08$ $\mathrm{mm})$ than on dorsum of left hand $(2.93 \pm 0.08 \mathrm{~mm}$ and $2.86 \pm 0.07 \mathrm{~mm}$ ) (Table 3). Also the mean \pm s.d thickness of basilic vein $(0.10 \pm 0.01 \mathrm{~mm})$ in either
Table 3. Diameter (in $\mathrm{mm}$ ) of Cephalic and Basilic Veins in Dorsum of Right and Left Hand.

\begin{tabular}{|c|c|c|c|c|c|c|c|c|}
\hline \multirow{2}{*}{ Veins } & \multicolumn{3}{|c|}{ Right } & \multicolumn{3}{|c|}{ Left } & \multirow[b]{2}{*}{ t-test } & \multirow[b]{2}{*}{ p-value } \\
\hline & $\mathbf{N}$ & Mean & SD & $\mathbf{N}$ & Mean & SD & & \\
\hline \multicolumn{9}{|c|}{ Based on External Circumference } \\
\hline Cephalic & 25 & 2.98 & 0.08 & 25 & 2.93 & 0.08 & 2.4 & 0.021 \\
\hline Basilic & 25 & 3.42 & 0.11 & 25 & 3.42 & 0.09 & 0.1 & 1 \\
\hline \multicolumn{9}{|c|}{ Based on Internal Circumference } \\
\hline Cephalic & 25 & 2.89 & 0.08 & 25 & 2.86 & 0.07 & 1.46 & 0.151 \\
\hline Basilic & 25 & 3.32 & 0.1 & 25 & 3.32 & 0.09 & 0.03 & 0.978 \\
\hline \multicolumn{9}{|c|}{ Thickness } \\
\hline Cephalic & 25 & 0.09 & 0.01 & 25 & 0.09 & 0.01 & 1.93 & 0.06 \\
\hline Basilic & 25 & 0.1 & 0.01 & 25 & 0.1 & 0.01 & -0.29 & 0.774 \\
\hline
\end{tabular}

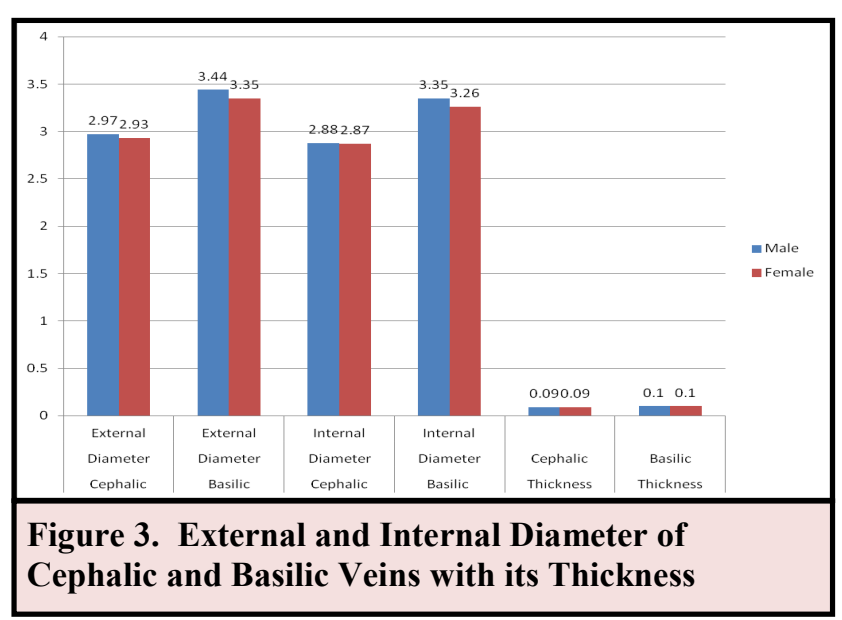

sex was greater than that of cephalic vein $(0.09 \pm 0.01 \mathrm{~mm})$ (Table 3, Figure 3).

\section{DISCUSSION}

The mean \pm s.d. length of dorsal venous arch in male cadavers was significantly greater $(19.03 \pm 2.84 \mathrm{~cm})$ than in female cadavers $(16.51 \pm 1.36 \mathrm{~cm})$ among dorsum of 50 hands of 25 cadavers available at Department of Anatomy, Kathmandu Medical College Teaching Hospital (KMCTH). There was no significant difference in length of dorsal venous arch on right $(18.22 \pm 2.47 \mathrm{~cm})$ and left side $(18.42 \pm 3.05 \mathrm{~cm})$ in either sex. Similar results of dorsal venous arch were published in the year 2012 researched by Taneja, Younus and Howale. ${ }^{7}$ They found the dorsal venous arch length in range of 9.5 to $20 \mathrm{~cm}$ on right hand and 10.2 to $17.7 \mathrm{~cm}$ on left hand. They also found the greater length of dorsal venous arch on right hand than on left hand. Our result showed slight difference in length of dorsal venous arch as our study sample was on cadavers and not on the living subjects. Other causes for the differences in result could be due to racial, social, ethnical background and dominant hand of the sample size. The observation of the present study was unlike that of other studies carried by Okamoto (1922), ${ }^{8}$ Matumato (1932), ${ }^{9}$ Halim et al $(1974)^{10}$, Haledon $\mathrm{M}$ et al (1995), ${ }^{11}$ Jasinski R (2003) ${ }^{12}$ and 
Ukoha UU et al $(2013)^{13}$ whose observation was on cephalic vein and not the diameter of the vein. The current study with mean diameter of cephalic vein (mean $2.9 \mathrm{~mm}$ ) nearly coincides with mean diameter of the vein (mean $4.5 \mathrm{~mm}$ ) as researched by Le Saout et al. ${ }^{14}$ Our result is dissimilar with the research performed on the diameter of the vein revealing higher range of the diameter of the vein ( $8 \mathrm{~mm}$ to $12 \mathrm{~mm}$ ) by Loukas $\mathrm{M}$ et al $(2008)^{15}$. The latest study done in year 2016 on revealing maximal diameter of upper limb superficial veins with an elevated environmental temperature also found greater mean diameter of basilic vein as 0.5 $\mathrm{cm}$ ( $5 \mathrm{~mm}$ ) near cubital fossa than cephalic vein at wrist as $0.28 \mathrm{~cm}(2.8 \mathrm{~mm})$ researched by Hira Irfan et al ${ }^{16}$. They observed greater value of basilic vein $(5 \mathrm{~mm})$ than in our research $(3.3 \mathrm{~mm})$. The causes for difference in diameter of the veins could be due to the measurement of diameter at different sites as we had researched the diameter based on external and internal circumferences at site of dorsal venous arch of hand on cadavers at room temperature and not on living individuals at the site of cubital fossa based on increase in temperature from 26 degree centigrade to 43 degree centigrade. Our study was unlike with the findings of mean thickness of cephalic vein at forearm $(0.33 \pm 0.10 \mathrm{~mm})$ and basilic vein $(0.29 \pm 0.06 \mathrm{~mm})$ as researched in the year 2013 by Kiray $\mathrm{A}$ et $\mathrm{al}^{17}$. The causes for difference in thickness could be due to the measurement at different sites as the present study researched the thickness at site of arch of hand on cadavers and not on forearm of cadavers.

\section{CONCLUSION}

The length of the dorsal venous arch in male cadavers was found to be significantly greater than in female cadavers. The mean diameters based on external and internal circumference of basilic veins was found to be more than diameter of cephalic veins in both male and female cadavers.

\section{Recommendations}

As only 50 hands of 25 cadavers were studied, this type of research needs to be studied in more number of cadavers available.

\section{Limitations}

The diameter of the cephalic and basilica veins is highly variable between subjects and often from day to day in the same subjects depending on hydration and body position. We were unable to observe such variations in cadavers.

\section{ACKNOWLEDGEMENTS}

I acknowledge to all the cadavers, supporting staffs and faculties at Department of Anatomy, Kathmandu Medical College, without whom this study would not have been successful.

None Conflict of Interest: None.

\section{REFERENCES}

1. Planken PN, Keuter $\mathrm{XH}$ et al.Diameter measurement of the forearm cephalic vein prior to vascular access creation in end stage renal disease patient: graduated pressure cuff versus torniquet vessel dilation. Nephral Dial Transplant.2006;21:802-06.

2. Hallock G. Superficial Venous Anastomosis in the human upper extremity. Folia morphal.1993;14:428-85.

3. Karuppal R, Raman RV, Vasu K. ServelleMartorell syndrome with excetensive upper limb involvement; a case report.J Med Case Rep.2008;2:142. doi: 10.1186/1752-1947-2-142

4. Alamshah SM. Cephalic vein anatomy in antecubital fossa during the construction of arteriovenous fistula. Acta Medica Iranica,2004;42(3):218-22.

5. Lirk P, Keller C.Unintentional arterial puncture during cephalic vein cannulation: Case Report and Anatomical Study. Br J Anaesth.2004;92:740 -42. https://dx.doi.org/10.1093/bja/aeh118

6. Kanagasuntheram R, Singham PS, Krishnamurti A. Textbook of Anatomy: Regional, functional and clinical. Orient longman,Madras.1996;25-27.

7. Taneja C, Younus M, Howale DS.The study of dorsal venous arch of hand in living adult males in Udaipur District of Rajasthan. Int.Journal of Current Research and review. 2012;04(05):8992.www.ijrc.com

8. Okamoto K. Anatomical Record. The arrangement of the superficial veins of the cubital fossa in Japanese men. Anat Rec1922;154:276-78. https://doi.org/10.1177\% 2F0268355516655670

9. Matumato N.Biostatistical study on the arrangement of the superficial veins of the cubital fossa in Japanese soldiers. Anat Rec1932;276: 302-306.

10.Halim A and Abdi SHM. Superficial Venous Pattern in cubital region of Indians. Anat Rec. 1974;178:631-36. https://doi.org/10.1002/ ar. 1091780310

11.Hagedorn M. In-vitro and in-vivo understanding. Folia morphal. 1995;46(5):31924.

12.Jasinski R, Paradnik E. Superficial venous anastomosis in the human upper extremity-a 
post morteum study. Folia Morphal. 2003;62(3)

$$
\begin{aligned}
& \text { 191-99. [Full Text] } \\
& \{10.1177 / 0268355516655670\}
\end{aligned}
$$

13.Ukoha UU, Oranusi CK, Okafor JI. Patterns of superficial venous arrangements in the cubital fossa of adult Nigerians. Niger J Clin Pract 2013;16:104-09. [Full Text] doi $=\{10.4103 / 1119$ $-3077.106777\}$

14.Le Saout J, Vallee B. Anatomical basis for the surgical use of the cephalic vein.J Chir,Paris.1983;120:131-34.[Pubmed]https:// www.ncbi.nlm.nih.gov/pubmed/6853618

15.Loukas M, Myers CS. The clinical anatomy of the cephalic vein in the deltopectoral triangle.FoliaMorphal.2008;67(1):72-77.

[FullText]https://journals.viamedica.pl/ folia_morphologica/article/view/16001

16.Irfan H, Ooi GS, Kyin M, Ho P. Revealing maximal diameter of Upper Limb Superficial Vein with an elevated environmental temperature. Int.J of ChronicDiseases.2016(4). [full Text] http:// dx.doi.org/10.1155/2016/8096473.

17. Kiray A, Ergur I, Tayefi H, Bagriyanik HA, Bacakoglu AK. Anatomical evaluation of the superficial veins of the upper extremity as graft donor source in microvascular reconstructions: a cadaveric study. Acta orthop Traumatol Turc 2013;47(6): 405-410. [Full Text] doi: 10.3944/ AOTT.2013.3194.

Citation: Tiwari N, Budhathoki D, Shrestha I, Timsina R, KS Shah, Malla KB. Morphology of Dorsal Venous Arch of Hand: A Cadaveric Study. JCMS Nepal. 2019; 15(2):139-43. 